\title{
Cyclodextrinase from Thermococcus sp expressed in Bacillus subtilis and its application in the preparation of maltoheptaose
}

Lei Wang ${ }^{1,2,3}$, Quan Wu $\mathbf{u}^{1,2,3}$, Kang Zhang ${ }^{1,2,3}$, Sheng Chen ${ }^{1,2,3}$, Zhengfei Yan ${ }^{1,2,3^{*}}$ and Jing $\mathrm{Wu}^{1,2,3^{*}}$

\begin{abstract}
Background: Maltoheptaose as malto-oligosaccharides with specific degree of polymerization, has wide applications in food, medicine and cosmetics industries. Currently, cyclodextrinase have been applied as prepared enzyme to prepare maltoheptaose. However, the yield and proportion of maltoheptaose was lower, which is due to limited substrate and product specificity of cyclodextrinase (CDase). To achieve higher maltoheptaose yield, cyclodextrinase with high substrate and product specificity should be obtained.

Results: In this study, cyclodextrinase derived from Thermococcus sp B1001 (TsCDase) was successfully expressed and characterized in Bacillus subtilis for the first time. The specific activity of TsCDase was $637.95 \mathrm{U} / \mathrm{mg}$ under optimal conditions of $90^{\circ} \mathrm{C}$ and $\mathrm{pH} 5.5$, which exhibited high substrate specificity for cyclodextrins (CDs). When the concentration of $\beta$-CD was $8 \%$, the yield of maltoheptaose achieved by TsCDase was $82.33 \%$ across all reaction products, which exceeded the yields of maltoheptaose in other recent reports. Among malto-oligosaccharides generated as reaction products, maltoheptaose was present in the highest proportion, about 94.55\%.
\end{abstract}

Conclusions: This study provides high substrate and product specificity of TsCDase. TsCDase is able to prepare higher yield of maltoheptaose through conversion of $\beta-C D$ in the food industry.

Keywords: Thermococcus sp B1001, Cyclodextrinase, Malto-oligosaccharides, Maltoheptaose

\section{Background}

Malto-oligosaccharides are composed of 2-10 glucose units connected by $\alpha-1,4$ linkages. They are considered to be important functional oligosaccharides that are beneficial for digestion and absorption in humans. Due to their good adaptability, malto-oligosaccharides have been widely applied as food additives in the food industry to improve the properties of food products, such as sweetness, hygroscopicity, stability, viscosity, and gelation $[1,2]$. Malto-oligosaccharides are usually obtained from starch as substrate by malto-oligosaccharide-forming

*Correspondence: zhengfeiyan@jiangnan.edu.cn; jingwu@jiangnan.edu.cn ${ }^{1}$ State Key Laboratory of Food Science and Technology, Jiangnan University, 1800 Lihu Avenue, Wuxi 214122, China

Full list of author information is available at the end of the article amylases [3]. However, adopting this route may yield malto-oligosaccharides with different polymerization degrees of oligosaccharides, resulting in the complex mixtures. Currently, it is difficult to prepare malto-oligosaccharides with specific degrees of polymerization using malto-oligosaccharide-forming amylases, because of the lack of substrate and product specificity.

At present, malto-oligosaccharides with a specific degree of polymerization, including maltotriose, maltotetraose and maltoheptaose, have a specific application, such as fast energy supply, anti-starch aging, and lowering osmotic pressure. Compared with that of maltotriose and maltotetraose, maltoheptaose has a lower osmotic pressure, higher viscosity, better moisturizing effect, and stronger film-forming performance, so that it has been widely applied in the food, medicine, cosmetics, and 
other fields [4], as well as being a saccharides-based candidate for block copolymers [5]. Thus, an investigation of enzymes with the substrate and product specificity is essential to achieve the mass production of high purity maltoheptaose.

There have so far been various reports of several malto-oligosaccharide-forming amylases that hydrolyze substrates to form maltoheptaose. Among substrates, cyclodextrins (CDs) are the most commonly used including $\alpha-C D, \beta-C D$, and $\gamma-C D$, which are composed of glucose units linked through $\alpha-\mathrm{D}-(1,4)$-glycosidic bonds. Three types of enzymes have been identified that efficiently hydrolyze CDs: cyclomaltodextrinase (CDase, EC 3.2.1.54), neopullulanase (NPase, EC 3.2.1.135), and maltogenic amylase (MAase, EC 3.2.1.133) [6]. These enzymes also hydrolyze other substrates, such as starch and pullulan, but with slower hydrolytic activity. This is may be due to 130 residues at the $\mathrm{N}$-terminus that might influence that catalytic efficiency of the active domain, and redundant 70 redundant residues at the $\mathrm{C}$-terminus that are absent in the $\alpha$-amylases. As their most preferred substrates are CDs, these enzymes have been proposed to have a single name, cyclodextrinase (CDases) [6]. At present, whole genome sequence analysis has been confirmed that CDases exist widely in various microorganisms, such as Bacillus coagulans [7], Anoxybacillus flavithermus [8], and Bacillus clarkii [9].

To date, heterologous expression of CDases has been investigated by using Escherichia coli only as the host. However, $E$. coli is an unsuitable host for use in the food industry, because of endotoxin production. Bacillus subtilis is a generally identified as a safe (GRAS) organism as it does not secrete toxins. B. subtilis as an emerging host exhibits no obvious codon preference and is capable of expression products secretion without inclusion bodies.

CDases have been reported to be a very effective enzyme for the production of maltoheptaose. Ji et al. described a novel CDase from Palaeococcus pacificus that prepare high purity maltoheptaose. Sequence alignment of CDase showed that Thermococcus sp B1001 CDase (TsCDase) have a high degree of similarity with $P$. pacificus CDase (Additional file 1: Figure S1). Previous studies also reported that TsCDase has higher catalytic efficiency for $\beta-C D$ than other substrates $[10,11]$. Thus, TsCDase may be a good candidate for maltoheptaose production using $\beta-C D$ as substrate. We chose to selecte Bacillus subtilis WS9 as the host strain for expression of TsCDase, and recombinant TsCDase was characterized in detail. The ability of TsCDase to produce high purity maltoheptaose using different concentrations of $\beta$-CD was also investigated. Compared with other CDases, TsCDase has achieved higher yield and purity maltoheptaose at high concentration of $\beta-C D$.

\section{Materials and methods}

\section{Reagents and chemicals}

Maltoheptaose, $\alpha-C D, \beta-C D, \gamma-C D$, soluble starch, and pullulan polysaccharide were purchased from SigmaAldrich (Shanghai, China). Taq DNA polymerase, protein and DNA size markers were purchased from Takara (Dalian, China). Unless otherwise noted, other chemicals were obtained from Sinopharm (Shanghai, China).

\section{Strains and plasmids}

The cyclodextrin hydrolase gene ( $t s c d$ ) from Thermofocus sp B1001 (GenBank accession number: BAB18100.1) was synthesized using pET-24a chemically, and named pET24a-tscd. E. coli JM109 was preserved in our laboratory for recombinant plasmid replication. B. subtilis WS9 and expression vector pUB110 were obtained from our laboratory for TsCDase expression.

\section{Construction of expression plasmids}

Two target fragments were amplified using pET-24a-tscd (primers IF/IR) and pUB110 (primers VF/VR) as templates, respectively. Based on these target fragments, the DNA multimers were generated to form recombinant plasmid pUB110-tscd (Fig. 1) by prolonged overlap extension PCR (POE-PCR) [12], which was duplicated in $E$. coli JM109. Recombinant plasmid pUB110-tscd was verified by sequencing, followed by expression in $B$. subtilis WS9 by the electroporation method [13]. B. subtilis WS9 with pUB110 was used applied as a control to determine successful TsCDase expression. All designed primers are listed in Table 1.

Production of TsCDase in B. subtlis WS9 and its purification A single colony of recombinant $B$. subtlis WS9 with pUB110-tscd was incubated as a seed culture in LB broth containing $100 \mu \mathrm{g} / \mathrm{mL}$ kanamycin, at $37^{\circ} \mathrm{C}, 200 \mathrm{rpm}$ for $8 \mathrm{~h}$. The seed culture $(2 \% \mathrm{v} / \mathrm{v})$ was added into $50 \mathrm{~mL} \mathrm{~TB}$ broth with $100 \mu \mathrm{g} / \mathrm{mL}$ kanamycin, at $37{ }^{\circ} \mathrm{C}, 200 \mathrm{rpm}$ for $2 \mathrm{~h}$, and then cultured for another $24 \mathrm{~h}$ at $33^{\circ} \mathrm{C}$. To purify TsCDase, whole-cell pellets were obtained by centrifuging at $12,000 \times g$ and $4{ }^{\circ} \mathrm{C}$ for $20 \mathrm{~min}$. They were then resuspended in $50 \mathrm{mM}$ Tris- $\mathrm{HCl}$ (pH 7.5) with $20 \mathrm{mg} / \mathrm{mL}$ lysozyme at $37{ }^{\circ} \mathrm{C}$ for $30 \mathrm{~min}$, followed by treatment in a high-pressure homogenizer. The supernatant of lysed cells that was obtained by centrifuging at $20,000 \times g$ and $4{ }^{\circ} \mathrm{C}$ for $10 \mathrm{~min}$, was heated at $90{ }^{\circ} \mathrm{C}$ for $15 \mathrm{~min}$ to precipitate denatured proteins. The pre-purified supernatant containing soluble TsCDase was obtained by centrifuging at $20,000 \times g$ and $4{ }^{\circ} \mathrm{C}$ for $20 \mathrm{~min}$, and was further purified using a nickel-nitrilotriacetic acid (Ni-NTA) column. Bound protein was eluted with a linear gradient of $0-300 \mathrm{mM}$ imidazole in $50 \mathrm{mM}$ Tris- $\mathrm{HCl}, 300 \mathrm{mM}$ $\mathrm{NaCl}$, at $\mathrm{pH}$ 7.5. Purified protein was verified by sodium 

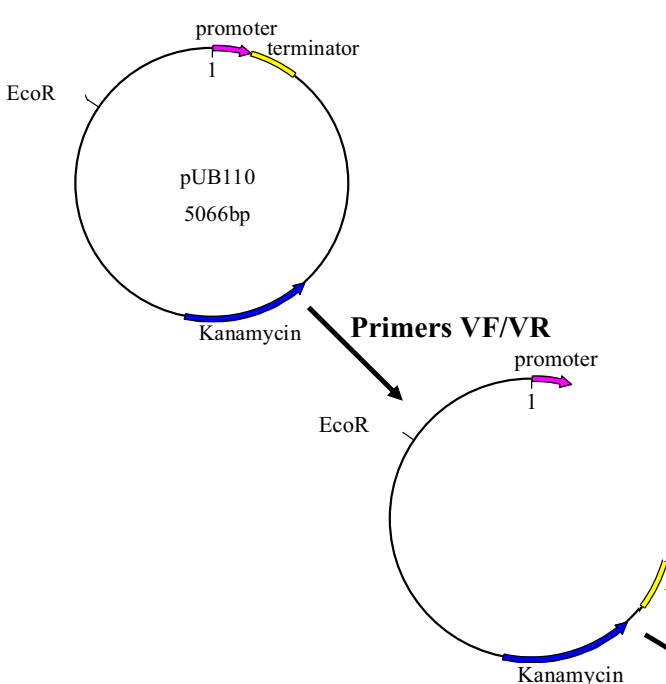

term

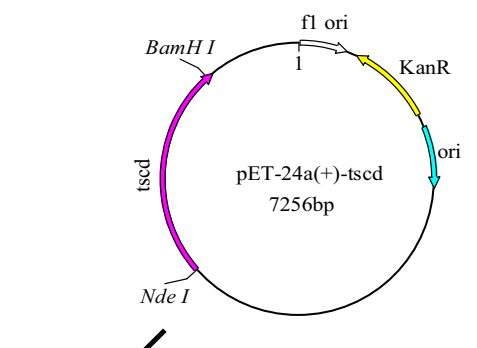

Primers IF/IR

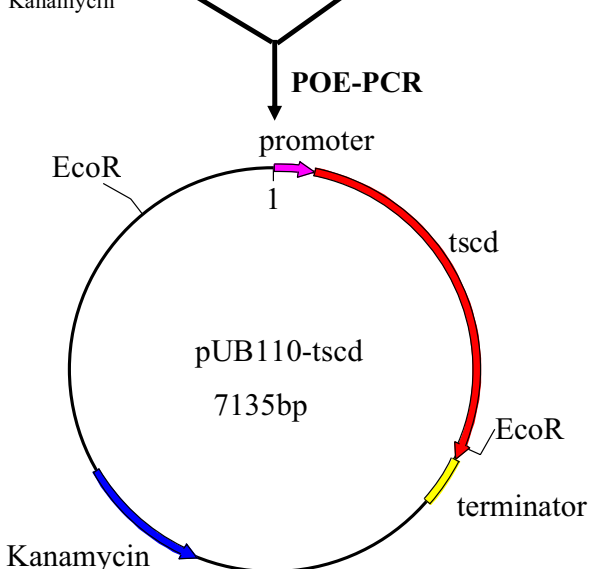

Fig. 1 The construction of recombinant plasmid pUB110-tscd

Table 1 Primers used to amplify the target gene and vector

\begin{tabular}{ll}
\hline Primers & Sequences \\
\hline IF & TAAGAAAATGAGAGGGAGAGGAAACATGTATAAAATTTTTGGCTTTAAAG \\
IR & AGCTTGGAGGTGTTTTTTATTACCGCTTTGTTAGCAGCCGGATCTCAGT \\
VF & ACTGAGATCCGGCTGCTAACAAAGCGGTAATAAAAAAACACCTCCAAGCT \\
VR & $\underline{\text { CTTTAAAGCCAAAAATTTATACATGTTTCCTCTCCCTCTCATTTTCTTA }}$ \\
\hline
\end{tabular}

Homologous arms are underlined

dodecyl sulfate-polyacrylamide gel electrophoresis (SDS-PAGE) analysis [14], and its concentration was estimated by the Bradford method [15].

\section{Enzyme activity of TsCDase}

The enzyme activity of TsCDase was measured, according to the sum of reducing sugars. In the assay mixture, $1.9 \mathrm{~mL}$ of $2 \% \beta-\mathrm{CD}(\mathrm{w} / \mathrm{v})$ was pre-treated in $50 \mathrm{mM}$
Tris- $\mathrm{HCl}$ buffer $\left(\mathrm{pH} \mathrm{7.5)}\right.$ at $90{ }^{\circ} \mathrm{C}$ for $10 \mathrm{~min}$, and then mixed with $100 \mu \mathrm{L}$ TsCDase for $10 \mathrm{~min}$. After stopped by ice water, reducing sugars were estimated by dinitrosalicylic acid (DNS) method [16].

\section{Effect of $\mathrm{pH}$ and temperature on TsCDase activity}

To determine optimal $\mathrm{pH}$ of TsCDase, relative activity of TsCDase in buffers of various $\mathrm{pH}$ values $(4.0-8.0)$ were 
investigated at $90{ }^{\circ} \mathrm{C}$ by method described above. TsCDase was incubated at pH 5.0-9.0 and $4{ }^{\circ} \mathrm{C}$ for $24 \mathrm{~h}$, and relative activity was determined to measure $\mathrm{pH}$ stability at $90{ }^{\circ} \mathrm{C}$ by method described above. The optimal temperature of TsCDase activity was determined at different temperatures $\left(75-100{ }^{\circ} \mathrm{C}\right)$ in $50 \mathrm{mM} \mathrm{pH} 7.5$ Tris- $\mathrm{HCl}$ buffer by method described above. The thermostability of TsCDase was determined by incubating TsCDase for $180 \mathrm{~min}$ at optimal temperature in $50 \mathrm{mM} \mathrm{pH} \mathrm{7.5} \mathrm{Tris-} \mathrm{HCl}$ buffer, followed by cooling the solution on ice water, and relative activity was determined at $30 \mathrm{~min}$ intervals by method described above.

\section{Substrate specificity of TsCDase}

The substrate specificity of TsCDase was determined against $\alpha-C D, \beta-C D, \gamma-C D$, soluble starch and pullulan polysaccharide. These substrates were dissolved in $50 \mathrm{mM}$ sodium phosphate buffer $(\mathrm{pH} 6.0)$ at a final concentration of $1 \%(\mathrm{w} / \mathrm{v})$, and after the addition of TsCDase $(0.3 \mu \mathrm{g})$, incubated at $90{ }^{\circ} \mathrm{C}$ for $10 \mathrm{~min}$. After stopping the reaction by ice water, and then relative activity of TsCDase was determined by method described above.

\section{Preparation of maltoheptaose using TsCDase}

TsCDase was used to prepare maltoheptaose with $\beta-C D$ as substrate. The effect of different concentrations of $\beta$-CD $(2 \%, 4 \%, 6 \%, 8 \%, 10 \%$, and $12 \% \mathrm{w} / \mathrm{v})$ on the preparation of maltoheptaose was investigated at $90{ }^{\circ} \mathrm{C}, 150 \mathrm{rpm}, \mathrm{pH}$ 5.5 for $4 \mathrm{~h}$ by adding TsCDase ( $2.8 \mathrm{U}$ ) to a final volume of $30 \mathrm{~mL}$. The enzymatic reaction was stopped by adding 250 $\mu \mathrm{L}$ of $0.4 \mathrm{M} \mathrm{NaOH}$, followed by neutralization with $0.4 \mathrm{M}$ $\mathrm{HCl}$. Excess $\beta-\mathrm{CD}$ was removed as a precipitate from the reaction mixture after adding acetonitrile for $2 \mathrm{~h}$ at room temperature. The supernatant that collected by centrifuging at $20,000 \times g$ and $4{ }^{\circ} \mathrm{C}$ for $20 \mathrm{~min}$, was characterized by HPLC as described below.

\section{Identification of the reaction products by HPLC}

The supernatant was detected by HPLC using a RID$10 \mathrm{~A}$ detector, and an APS-2 HYPERSIL column $\left(250 \mathrm{~mm} \times 4.6 \mathrm{~mm}\right.$, Agilent) was used at $30{ }^{\circ} \mathrm{C}$. Acetonitrile/water $(80: 20, \mathrm{v} / \mathrm{v})$ was applied as the mobile phase with a flow rate of $0.8 \mathrm{~mL} / \mathrm{min}$.

\section{Statistical analysis}

All experiments were repeatedly carried out three times, and the results are presented as the means \pm standard deviations.

\section{Results and discussion}

\section{Gene expression in B. subtilis WS9 and purification of TsCDase}

TsCDase from Thermococcus sp B1001 (approximately $66 \mathrm{kDa}$ ) was first successfully expressed in B. subtilis
WS9, which was widely found in the intracellular compartment of recombinant B. subtilis WS9 (Fig. 2). Only partial TsCDase as soluble protein were in the supernatant of lysed cells, whose activity was approximately $5.9 \mathrm{U} / \mathrm{mL}$ with specific activity of $45.24 \mathrm{U} / \mathrm{mg}$ (Fig. 2a Lane 2). Most TsCDase as inclusion bodies in sediment of lysed cells, but with no activity (Fig. 2a Lane 3). TsCDase in the supernatant of lysed cells was purified with a combined purification protocol by heat treatment and a Ni-NTA column (Fig. 2b). After heat treatment at $90{ }^{\circ} \mathrm{C}$ for $15 \mathrm{~min}$, the level of recovery was $91.47 \%$ with $76.75 \mathrm{U} / \mathrm{mg}$ of protein. This might be because the heat treatment was able to denature and precipitate almost proteins from the host to improve the purity of soluble TsCDase in the soluble fraction, which was consistent with previous study [17]. Meanwhile, high temperature also could promote the formation of proper protein folding of TsCDase, which could enhance its enzyme activity. Without heat treatment, TsCDase was in an intermediate stage of protein folding with slight activity, which was also observed in CDases from Pyrococcus furiosus and $P$. pacificus $[17,18]$. Subsequently, TsCDase was further purified using a Ni-NTA column with $637.95 \mathrm{U} / \mathrm{mg}$ of protein (Table 2). TsCDase activity was greater than that of CDase described by Li et al., as well as its specific activity [19].

\section{Effect of $\mathrm{pH}$ and temperature on TsCDase activity}

The effect of various $\mathrm{pH}(4.0-8.0)$ on TsCDase activity was investigated by using $\beta-C D$ as the substrate. The optimal $\mathrm{pH}$ for enzyme activity was detected to be $\mathrm{pH} 5.5$, and relative activity at the $\mathrm{pH}$ range 5.5-6.0

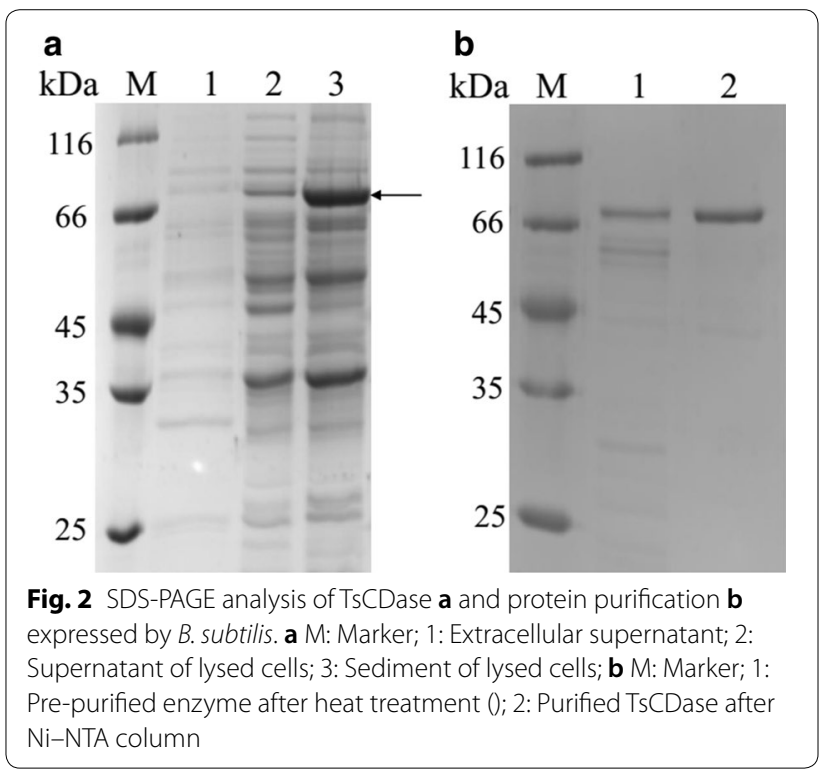


Table 2 Summary of the steps involved in purification of recombinant TsCDase

\begin{tabular}{|c|c|c|c|c|c|}
\hline Purification step & Total protein (mg) & Total activity (U) & $\begin{array}{l}\text { Specific activity (U/ } \\
\text { mg) }\end{array}$ & Purification-fold & Yield (\%) \\
\hline Cell lysate & 118.85 & 5376.83 & 45.24 & 1 & 100 \\
\hline Heat treatment & 64.08 & 4918.19 & 76.75 & 1.7 & 91.47 \\
\hline Ni-NTA column & 1.31 & 835.72 & 637.95 & 14.1 & 17 \\
\hline
\end{tabular}

was over $60.0 \%$ of maximum activity (Fig. 3a). The $\mathrm{pH}$ effect on TsCDase stability was obtained by incubation at $4{ }^{\circ} \mathrm{C}$ and $\mathrm{pH}$ 5.0-9.0 for $24 \mathrm{~h}$. Optimal TsCDase stability was observed at $\mathrm{pH}$ 8.0. Relative activity of TsCDase was stable at $\mathrm{pH} 7.5-9.0$, retaining over $60.0 \%$ of maximum activity, suggesting TsCDase was suitable for storage in weak alkaline buffer. TsCDase was active in the range $75-100{ }^{\circ} \mathrm{C}$ with an optimal temperature of $90{ }^{\circ} \mathrm{C}$ (Fig. 3). The optimal temperature of TsCDase was significantly different from other CDases, which have optimal temperatures of $35-65{ }^{\circ} \mathrm{C}[7,20,21]$. The thermostability of TsCDase was determined at $90{ }^{\circ} \mathrm{C}$. TsCDase retained over $80.0 \%$ of maximum activity after incubation for $20 \mathrm{~min}$, and its half-life was $120 \mathrm{~min}$. These results revealed the optimal catalytic conditions of TsCDase were $90{ }^{\circ} \mathrm{C}$ and $\mathrm{pH} 5.5$, which are the same
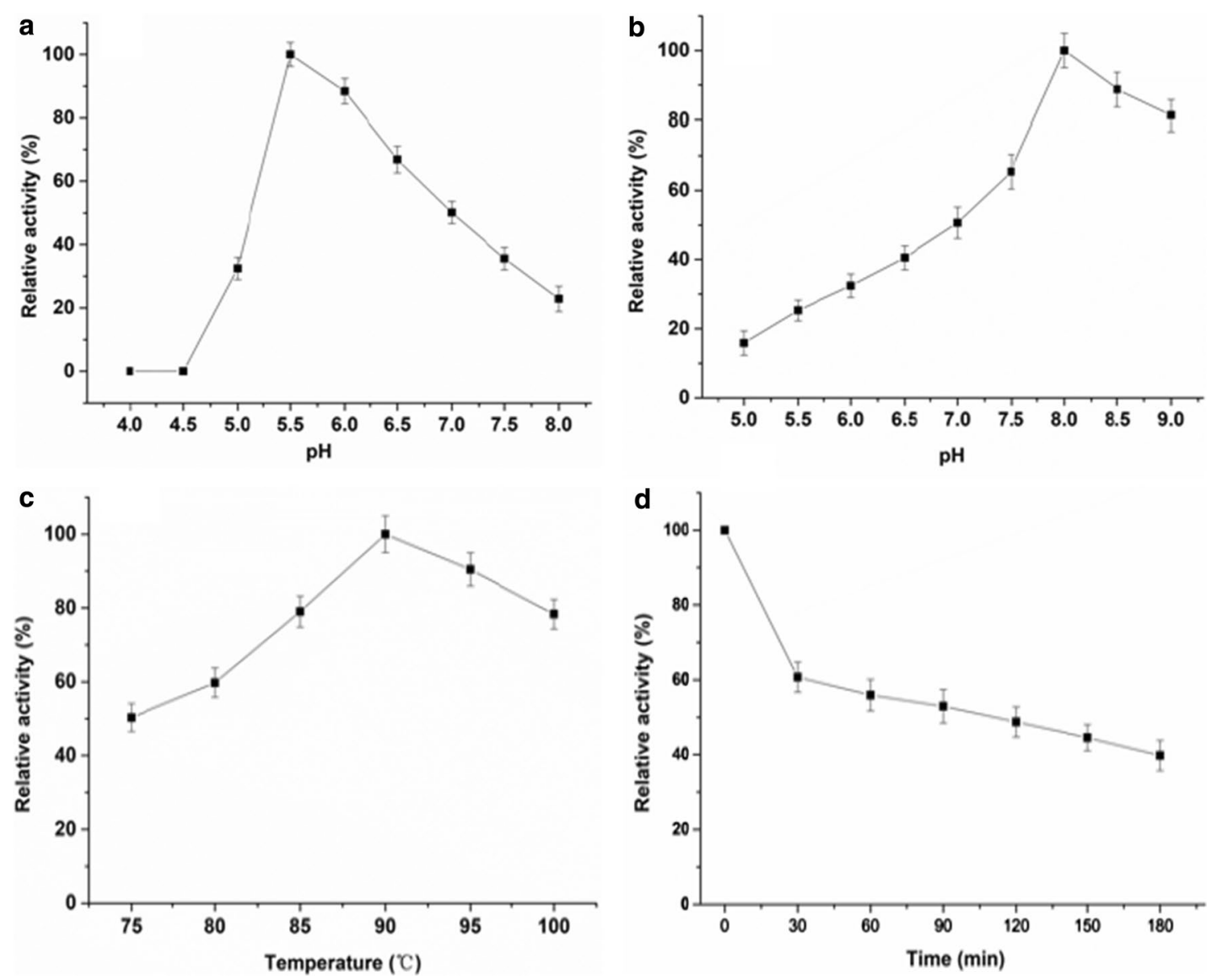

Fig. 3 Effect of $\mathrm{pH}$ and temperature on TsCDase activity. a) Effect of $\mathrm{pH}$ on TsCDase activity. The maximum activity detected at pH 5.5 was taken as 100\%. b Effect of pH on TsCDase stability. The maximum activity detected at $\mathrm{pH} 8.0$ was taken as $100 \%$. $\mathbf{c}$ Effect of temperature on TsCDase activity. The maximum activity detected at $90^{\circ} \mathrm{C}$ was taken as $100 \%$. d Thermostability of TsCDase. The thermostability of TsCDase was determined at $90{ }^{\circ} \mathrm{C}$ and TsCDase activity without incubation was taken as 100\% 
Table 3 Relative activity of TsCDase on different sustrates

\begin{tabular}{ll}
\hline Substrates & $\begin{array}{l}\text { Relative } \\
\text { activity } \\
\text { (\%) }\end{array}$ \\
\hline$\beta-C D$ & 100 \\
$a-C D$ & 80 \\
$\gamma-C D$ & 73 \\
Soluble starch & N.D. \\
Pullulan polysaccharide & N.D. \\
\hline
\end{tabular}

as for amylopullulanases from thermophilic archaea [22].

\section{Substrate specificity of TsCDase}

The specificity of TsCDase towards several substrates was given in Table 3. TsCDase showed its highest activity on $\beta-C D$ in comparison to $\alpha-C D$ and $\gamma-C D$, and no activity on soluble starch and pullulan polysaccharide, suggesting the strong substrate specificity of TsCDase for CDs. Its substrate specificity was similar to that of CDases from Paenibacillus sp [23]. However, the CDases from P. furiosus [24] and Thermofilum pendens [25] were reported to hydrolyze not only CDs, but also pullulan and soluble starch, as they were identified as multispecific enzymes that possessed the activities of both $\alpha$-amylase and a cyclodextrinase [26].

\section{Preparation of maltoheptaose by TsCDase}

In this study, the preparation of maltoheptaose was investigated using different concentrations of $\beta-C D$ as the substrate at $90^{\circ} \mathrm{C}, \mathrm{pH} 5.5$ for $4 \mathrm{~h}$. Insoluble $\beta$-CD was precipitated by adding acetonitrile to the reaction mixture at room temperature, which was consistent with a previous report [27]. As shown in Fig. 4, with increase of $\beta$-CD concentration, the production of maltoheptaose increased and achieved its maximum value at $8 \%$ $\beta-C D(w / v)$ with an $82.33 \%$ for yield of maltoheptaose in all reaction products and $94.55 \%$ for the proportion of maltoheptaose in malto-oligosaccharides. Compared with the result described by Ji et al. [17], TsCDase exhibited greater product specificity, and converted $\beta-C D$ to maltoheptaose at a high conversion rate $(82.33 \%)$, which is the highest yield achieved in the preparation of maltoheptaose by CDases. Interestingly, when $\beta-C D$ concentration was up to $12 \%$, yield of maltoheptaose also retained over $80.0 \%$ by TsCDase, indicating TsCDase has significant product specificity and be active at high concentrations of $\beta-C D$ with no substrate inhibition effect. Ji et al. reported that the enzymatic reaction of P. pacificus CDase was suppressed by a high concentration of $\beta-C D$ [17], which is significantly difference from the results of this study.

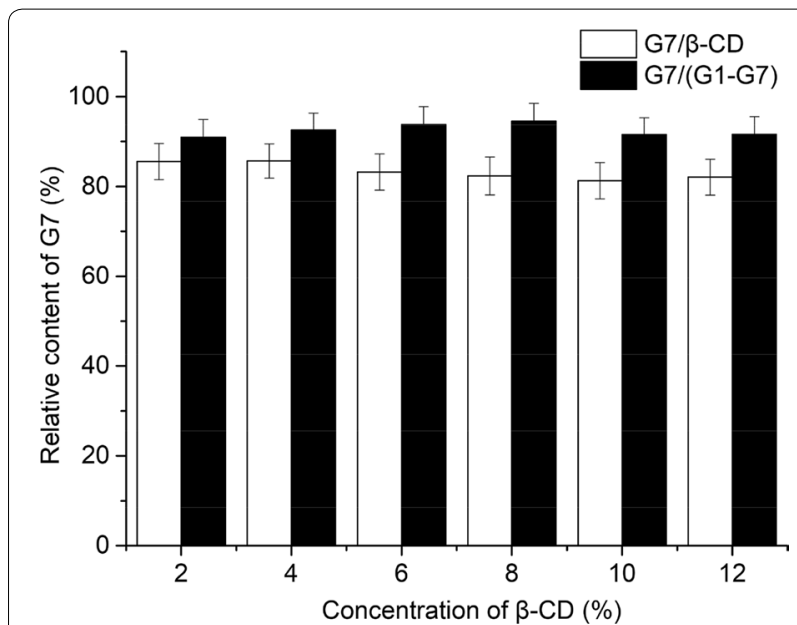

Fig. 4 Influence of substrate concentration on preparation of maltoheptaose. Reaction condition was $90^{\circ} \mathrm{C}, 150 \mathrm{rpm}, \mathrm{pH} 5.5$ for $4 \mathrm{~h}$ with TsCDase (2.8 U) in final volume of $30 \mathrm{~mL}$. $\square$ indicated yield of maltoheptaose in all reaction products. indicated the proportion of maltoheptaose in malto-oligosaccharides

\section{Conclusions}

A cyclodextrinase (TsCDase) from Thermococcus sp B1001 was successfully expressed in B. subtilis for the first time. The results indicated that TsCDase had optimal activity at $\mathrm{pH} 5.5$ and $90{ }^{\circ} \mathrm{C}$, and was extremely thermostable. TsCDase has unique substrate and product specificities, which provide advantages in the preparation of maltoheptaose by using $\beta-C D$ as substrate. When the concentration of $\beta-C D$ was $8 \%$ under the the optimal conditions of $90{ }^{\circ} \mathrm{C}$ and $\mathrm{pH} 5.5$ for $4 \mathrm{~h}$, the maximum yield of maltoheptaose in all reaction products was $82.33 \%$, and the proportion of maltoheptaose in the malto-oligosaccharides-products was $94.55 \%$. Therefore, TsCDase has potential value in the preparation of maltoheptaose in the food industry as it can provide a specific polymerization degree of malto-oligosaccharides.

\section{Supplementary information}

Supplementary information accompanies this paper at https://doi. org/10.1186/s12934-020-01416-y.

Additional file 1: Figure S1. Protein sequence analysis of cyclodextrins from various sources.

\section{Abbreviations}

CDase: Cyclodextrinase; TsCDase: Cyclodextrinase from Thermococcus sp

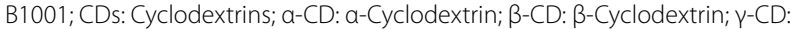
$\gamma$-Cyclodextrin; tscd: Cyclodextrin hydrolase gene; DNS: 3,5-Dinitrosalicylic acid; SDS-PAGE: Sodium dodecyl sulfate-polyacrylamide gel electrophoresis.

Acknowledgements

Not applicable. 


\section{Authors' contributions}

LW, QW and KZ designed and carried out the experiments, drafted the manuscript; SC, JW and ZFY supervised the project and revised the manuscript. All authors read and approved the final manuscript.

\section{Funding}

This work received financial support from National Natural Science Foundation of China (31730067), Fundamental Research Funds for the Central Universities (JUSRP51706A), National First-Class Discipline Program of Light Industry Technology and Engineering (LITE2018-03), 111 Project (No. 111-206), Fundamental Research Funds for the Central Universities (JUSRP11968).

\section{Ethics approval and consent to participate}

Not applicable.

\section{Consent for publication}

Not applicable.

\section{Competing interests}

The authors declare that they have no competing interests.

\section{Author details}

1 State Key Laboratory of Food Science and Technology, Jiangnan University, 1800 Lihu Avenue, Wuxi 214122, China. ${ }^{2}$ School of Biotechnology and Key Laboratory of Industrial Biotechnology Ministry of Education, Jiangnan University, 1800 Lihu Avenue, Wuxi 214122, China. ${ }^{3}$ International Joint Laboratory on Food Safety, Jiangnan University, 1800 Lihu Avenue, Wuxi 214122, China.

Received: 4 June 2020 Accepted: 24 July 2020

Published online: 01 August 2020

\section{References}

1. Marchal LM, Beeftink HH, Tramper J. Towards a rational design of commercial maltodextrins. Ahan. 1999;10:345-55.

2. Xu Q, Chao YL, Wan QB. Health benefit application of functional oligosaccharides. Carbohydr Polym. 2009;77:435-41.

3. Messaoud EB, Ali MB, Elleuch N, Masmoudi NF, Bejar S. Purification and properties of a maltoheptaose- and maltohexaose-forming amylase produced by Bacillus subtilis US116. Enzyme Microb Technol. 2004;34:662-6.

4. Kobayashi K, Sumitomo H, Itoigawa T. Maltopentaose-and maltoheptaose-carrying styrene macromers and their homopolymers. Macromolecules. 1987;20:906-8.

5. Li BG, Zhang LM. Synthesis and characterization of novel amphiphilic block copolymers based on maltoheptaose and poly( $\varepsilon$-caprolactone) Carbohydr Polym. 2008;74:390-5.

6. Park KH, Kim TJ, Cheong TK, Kim JW, Svensson B. Structure, specificity and function of cyclomaltodextrinase, a multispecific enzyme of the a-amylase family. Biochim Biophys Acta. 2000;1478:165-85.

7. Sumio K, Michio T, Duque BS, Toshiyuki S, Shigetaka O. Purification and some properties of cyclodextrinase from Bacillus coagulans. Agric Biol Chem. 1983;47:1441-7.

8. Turner P, Labes A, Fridjonsson $\mathrm{OH}$, Hreggvidson $\mathrm{GO}$, SchNheit P, Kristjansson JK, Holst O, Karlsson EN. Two novel cyclodextrin-degrading enzymes isolated from thermophilic bacteria have similar domain structures but differ in oligomeric state and activity profile. J Biosci Bioeng. 2005.100.

9. Nakagawa Y. Gene cloning and enzymatic characteristics of a novel Y-cyclodextrin-specific. Biochim Biophys Acta Proteins Proteomics. 2008;1784(12):2004-11.

10. Tachibana Y, Kuramura A, Shirasaka N, Suzuki Y, Yamamoto T, Fujiwara S, Takagi M, Imanaka T. Purification and characterization of an extremely thermostable cyclomaltodextrin glucanotransferase from a newly isolated hyperthermophilic archaeon, a Thermococcus sp. Appl Environ Microbiol. 1999:65:1991-7.

11. Hashimoto Y, Yamamoto T, Fujiwara S, Takagi M, Imanaka T. Extracellular synthesis, specific recognition, and intracellular degradation of cyclomaltodextrins by the hyperthermophilic archaeon Thermococcus sp. strain B1001. J Bacteriol. 2001:183:5050-7.

12. You C, Zhang $X Z$, Zhang $Y H$. Simple cloning via direct transformation of PCR product (DNA Multimer) to Escherichia coli and Bacillus subtilis. Appl Environ Microbiol. 2012;78:1593-5.

13. Turgeon N, Laflamme C, Ho J, Duchaine C. Elaboration of an electroporation protocol for Bacillus cereus ATCC 14579. J Microbiol Methods. 2006;67:543-8.

14. Laemmli UK. Cleavage of structural proteins during the assembly of the head of bacteriophage T4. Nature. 1970;227:680-5.

15. Bradford MM. A rapid and sensitive method for the quantitation of microgram quantities of protein utilizing the principle of protein-dye binding Anal Biochem. 1976;72:248-54

16. Bernfeld P. Amylases alpha and beta. Methods Enzymol. 1955;1:140-6

17. Ji H, Bai Y, Li X, Wang J, Xu X, Jin Z. Preparation of malto-oligosaccharides with specific degree of polymerization by a novel cyclodextrinase from Palaeococcus pacificus. Carbohydr Polym. 2019;210:64-72.

18. Lee MH, Yang SJ, Kim JW, Lee HS, Kim JW, Park KH. Characterization of a thermostable cyclodextrin glucanotransferase from Pyrococcus furiosus DSM3638. Extremophiles. 2007;11:537-41.

19. Li X, Li D. Preparation of linear maltodextrins using a hyperthermophilic amylopullulanase with cyclodextrin- and starch-hydrolysing activities. Carbohydr Polym. 2015;119:134-41.

20. Podkovyrov SM, Zeikus JG. Structure of the gene encoding cyclomaltodextrinase from Clostridium thermohydrosulfuricum $39 \mathrm{E}$ and characterization of the enzyme purified from Escherichia coli. J Bacteriol. 1992;174:5400-5.

21. Kim TJ, Shin JH, Oh JH, Kim MJ, Lee SB, Ryu S, Kwon K, Kim JW, Choi EH, Robyt JF. Analysis of the gene encoding cyclomaltodextrinase from Alkalophilic Bacillus sp. I-5 and characterization of enzymatic properties. Arch Biochem Biophys. 1998;353:221-7.

22. Li X, Li D, Park KH. An extremely thermostable amylopullulanase from Staphylothermus marinus displays both pullulan- and cyclodextrindegrading activities. Appl Microbiol Biotechnol. 2013;97:5359-69.

23. Kaulpiboon J, Pongsawasdi P. Expression of cyclodextrinase gene from Paenibacillus sp. A11 in Escherichia coli and characterization of the purified cyclodextrinase. J Biochem Mol Biol. 2004;37:408-15.

24. Yang SJ, Lee HS, Park CS, Kim YR, Moon TW, Park KH. Enzymatic analysis of an amylolytic enzyme from the hyperthermophilic archaeon Pyrococcus furiosus reveals its novel catalytic properties as both an alpha-amylase and a cyclodextrin-hydrolyzing enzyme. Appl Environ Microbiol. 2004;70:5988-95.

25. Li X, Li D, Yin Y, Park KH. Characterization of a recombinant amylolytic enzyme of hyperthermophilic archaeon Thermofilum pendens with extremely thermostable maltogenic amylase activity. Appl Microbiol Biotechnol. 2010:85:1821-30.

26. Koo YS, Ko DS, Jeong DW, Shim JH. Development and application of cyclodextrin hydrolyzing mutant enzyme which hydrolyzes $\beta$ - and $\gamma$-CD selectively. J Agric Food Chem. 2017;65:2331-6.

27. Grard S, Elfakir C, Dreux M. Characterization of sulfobutyl ether-betacyclodextrins mixtures by anion-exchange chromatography using evaporative light scattering detection. J Chromatogr A. 2000;897:185-93.

\section{Publisher's Note}

Springer Nature remains neutral with regard to jurisdictional claims in published maps and institutional affiliations. 